\title{
PELATIHAN PEMBUATAN KUIS EDUKATIF SEBAGAI PENUNJANG PENGUASAAN PEMBELAJARAN DARING BAGI GURU SMP DI KECAMATAN NARMADA DAN LINGSAR LOMBOK BARAT NUSA TENGGARA BARAT
}

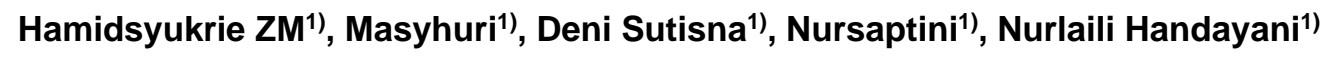 \\ 1)Program Studi Pendidikan Sosiologi, FKIP, Universitas Mataram, Mataram, NTB, Indonesia \\ Corresponding author : Deni Sutisna \\ E-mail : denisutisna@unram.ac.id
}

Diterima 07 Oktober 2021, Direvisi 02 November 2021, Disetujui 02 November 2021

\begin{abstract}
ABSTRAK
Kompetensi dan keahlian guru dalam memanfaatkan teknologi sangat diperlukan untuk meraih keberhasilan dalam pembelajaran daring. Meski demikian tidak semua guru mampu cepat beradaptasi dalam menggunakan aplikasi-aplikasi pembelajaran. Pengabdian ini bertujuan untuk memberikan penyuluhan dan pelatihan serta bimbingan kepada guru agar memiliki kemampuan dalam melaksanakan pembelajaran dan evaluasi yang menyenangkan berbantukan aplikasi Quizziz. Metode yang digunakan dalam kegiatan ini meliputi 3 tahapan, diantaranya: kegiatan awal, kegiatan inti, dan kegiatan akhir. Kegiatan awal meliputi observasi dan FGD bersama mitra dan tim, kegiatan inti adalah pelaksanaan pelatihan, dan ketiga adalah tindak lanjut. Hasil kegiatan ini menunjukkan dimana kemampuan peserta pelatihan mengalami peningkatan yang sangat signifikan. Data awal menunjukkan pada aspek pengetahuan awal terhadap aplikasi hanya $13 \%$ diantara mereka yang mengetahui aplikasi Quizziz dan hal tersebut meningkat menjadi $100 \%$ setelah pelaksanaan pelatihan. Selanjutnya pada aspek pemahaman, sebelum dilaksanakan pelatihan hanya $8 \%$ peserta yang memahami aplikasi Quizziz dan setelah pelaksanaan pelatihan meningkat menjadi 70\%. Dan terakhir ketertarikan dimana sebelum pelaksanaan pelatihan hanya $26 \%$ peserta yang menyatakan tertarik menggunakan aplikasi Quizziz dan setelah pelaksanaan pelatihan mengalami peningkatan menjadi $89 \%$. Berdasarkan data tersebut dapat disimpulkan bahwa kegiatan pengabdian ini berjalan dengan baik dan berhasil meningkatkan pengetahuan, pemahaman, dan minat atau ketertarikan peserta dalam penggunaan aplikasi Quizziz pada pembelajaran.
\end{abstract}

Kata kunci: pembelajaran daring; teknologi pembelajaran, aplikasi pembelajaran; quizziz .

\begin{abstract}
The competence and expertise of teachers in utilizing technology is needed to achieve success in online learning. However, not all teachers are able to quickly adapt in using learning applications. This service aims to provide counseling and training as well as guidance to teachers so that they have the ability to carry out fun learning and evaluations using the Quizziz application. The method used in this activity includes 3 stages, including: initial activity, core activity, and final activity. Initial activities include observation and Focus Group Discussion with partners and teams, the core activity is the implementation of training, and the third is follow-up activities. The results of this activity indicate where the ability of the training participants has increased very significantly. Preliminary data shows that in the aspect of initial knowledge only $13 \%$ of participants know the Quizziz application and eventually it increases to $100 \%$ after the training. Next on the aspect of understanding. before the training was carried out only $8 \%$ of participants understood the Quizziz application and after the training it increased to $70 \%$. And lastly, interest, where before the training only $26 \%$ of participants expressed interest in using Quizziz and after the training increased to $89 \%$. Based on these data, it can be concluded that this service activity went well and succeeded in increasing the knowledge, understanding, and interest of participants in using the Quizziz application for learning.
\end{abstract}

Keywords: online learning; learning technology, learning applications; quizziz

\section{PENDAHULUAN}

Pendidikan merupakan sebuah proses untuk memanusiakan manusia. sebagaimana diketahui bahwa manusia terlahir dengan minat, bakat dan kemampuan yang berbeda, di sinilah pendidikan berperan untuk membentuk manusia menjadi lebih akan potensi yang dimilikinya melalui proses pembelajaran dan/atau cara lain yang dikenal dan diakui oleh masyarakat. Sebagaimana yang diatur dalam 
Undang-undang dasar negara Republik Indonesia tahun 1945 Pasal 31 ayat (1) menyebutkan bahwa setiap warga Negara berhak mendapat pendidikan.

Proses pendidikan memiliki tujuan yang ingin dicapai seperti ranah kognitif, ranah afektif, dan ranah psikomotorik, (Makki \& Affaandi, 2019). Untuk mencapai ketiga ranah tersebut diperlukan kemampuan manajerial guru yang baik dalam pengelolaan kelas. Indonesia merupakan sebuah negara yang selau berusaha untuk meningkatkan kualitas pendidikan melalui inovasi-inovasi pendidikan, namun karena disebabkan oleh beberapa hal seperti bencana, salah satunya pandemi Covid19 yang muncul pada akhir tahun 2019 dan mewabah di negara Indonesia mulai tahun 2020 berdampak pada pelaksanaan pembelajaran di Indonesia. Wabah COVID 19 ini melumpuhkan kegiatan belajar mengajar pada instansi pendidikan dan menyebabkan sarana pengembangan diri siswa di sekolah juga ikut hilang, (Pohan, 2020)

Pandemi yang menyebabkan terganggunya sektor pendidikan, memaksa Menteri Pendidikan dan Kebudayaan Republik Indonesia mengeluarkan Surat Edaran Nomor 4 Tahun 2020 tentang pelaksanaan kebijakan pendidikan dalam masa darurat penyebaran COVID 19, dalam surat Edaran tersebut dijelaskan bahwa proses belajar dilaksanakan di rumah melalui pembelajaran daring. Hal itu dilaksanakan sebagai upaya pemerintah agar siswa masih dapat mendapatkan layanan pendidikan dan pembelajaran meskipun dilaksanakan secara daring.

Pandemi yang dialami dunia khususnya bangsa Indonesia, belum ada yang mengetahui kapan berakhir, sehingga agar proses pembelajaran tetap dapat berlangsung dipilih alternatif melalui pembelajaran daring. Pembelajaran daring diterapkan pada semua jenjang pendidikan mulai dari PAUD hingga perguruan tinggi. Hal tersebut dimaksudkan untuk menekan angka penyebaran pandemi covid-19 di sekolah.

Meskipun pembelajaran daring sudah berjalan lebih dari 3 semester, nyatanya masih menyisakan permasalahan. Telah banyak penelitian terkait problematika pembelajaran daring, diantaranya yang mengkaji kurangnya efektivitas belajar yang di hasilkan oleh (Fauziyah, 2020) (Oktavian \& Aldya, 2020) ,(Hikmat, Hermawan, Aldim, \& Irwandi, 2020)permasalahan teknis seperti jaringan dan kurangnya media pembelajaran yang merupakan hasil kajian dari (Hikmat et al., 2020), (Juliya \& Herlambang, 2021) dan juga kurangnya kemampuan manajerial guru atau dosen dalam pengelolaan kelas daring yang telah dikaji oleh (Juliya \& Herlambang, 2021),(Santaria \& Setiawan, 2020) dan (Widodo, Nursaptini, Novitasari, Sutisna, \& Umar, 2020)

Begitu pula yang terjadi pada sekolahsekolah yang terdapat di Kecamatan Lingsar dan Kecamatan Narmada kabupaten Lombok Barat. Setelah kami melakukan observasi, permasalahan-permasalahan tersebut diatas masih di temukan. Belum lagi hingga saat ini guru belum menemukan formulasi yang tepat dalam melaksanakan pembelajaran daring terutama variasi dalam pelaksanaan penilaian dan evaluasi. Oleh karena itu kami berinisiatif untuk mengadakan bimbingan, penyuluhan dan pelatihan untuk meningkatkan kompetensi guru dalam bidang pembelajaran daring terutama dalam melaksanakan evaluasi atau penilaian pembelajaran.

Kegiatan pengabdian ini terfokus pada pelatihan dalam menggunakan salah satu aplikasi pembelajaran yaitu Quizziz. Aplikasi ini dipilih berdasarkan hasil pengalaman dan perbandingan dari berbagai aplikasi yang dugunakan. Kelebihan dari aplikasi ini yaitu cara pembuatannya itu cukup mudah dan sederhana serta tidak memerlukan memori gadget yang besar(Kusumadewi, Yustiana, \& Nasihah, 2020). Selain itu aplikasi Quizziz ini mudah di gunakan dan bisa diadaptasi oleh semua jenjang mulai dari sekolah dasar hingga perguruan tinggi

Kegiatan pengabdian ini bertujuan untuk memberikan keterampilan kepada guru yang berada di wilayah kecamatan lingsar dan kecamatan Narmada khususnya pada SMPN 3 Lingsar dan SMPS Darussalam Plus Narmada. Selain itu kegiatan diharapkan mampu memberikan kontribusi dalam pengembangan kemampuan pengelolaan kelas guru terutama dalam pelaksanaan evaluasi dan penilaian sehingga diharapkan mampu meningkatkan aktivitas, kreativitas serta menumbuhkan motivasi belajar siswa.

\section{METODE}

Kegiatan ini dilaksanakan dengan menggandeng mitra dari 2 sekolah berbeda yaitu perwakilan dari sekolah menengah pertama yang di wakili oleh SMPN 3 Lingsar serta sekolah menegah pertama dari kecamatan Narmada yang diwakili oleh SMP Darussalam Plus. Adapun jumlah partisipan yang mengikuti kegiatan ini berjumlah 35 orang baik yang berasal dari SMPN 3 Lingsar dan SMPN 3 Narmada.

Teknik yang digunakan dalam kegiatan ini secara daring dengan memanfaatkan aplikasi Zoom meeting. Metode dilakukan dengan 2 cara baik secara sinkronus 
(langsung), maupun asinkronus (tidak Langsung).

Ada beberapa tahapan dalam pelaksanaan kegiatan ini. Tahapan tersebut diantaranya tahapan persiapan, pelaksanaan, dan evaluasi. pada tahap persiapan kami mencoba mempersiapkan segala kebutuhan untuk pelaksanaan pelatihan mulai dari administrasi, materi, dan tentunya koordinasi dengan mitra yaitu guru. Kedua tahapan pelaksanaan. Seperti yang telah di katakan diatas bahwa pelaksanaan pelatihan ini dilaksanakan secara daring dengan metode sinkronus dan asinkrous. Ada 3 fase dalam pelaksanaan kegiatan yang meliputi: pembekalan, penyuluhan materi tentang pembelajaran daring, dan pelatihan. Setelah kegiatan tersebut kita membuka forum diskusi.

Untuk evaluasi kegiatan kami mengirimkan pertanyaan berupa postest untuk meninjau keberhasilan kegiatan ini dengan melihat respon dari peserta kegiatan. Selain itu kami juga melakukan monitoring dengan berkunjung langsung ke sekolah mitra untuk meninjau kemampuan dalam menggunakan aplikasi yang telah di dipelajari. Secara detail skema pelatihan bisa di lihat pada gambar di bawah ini.

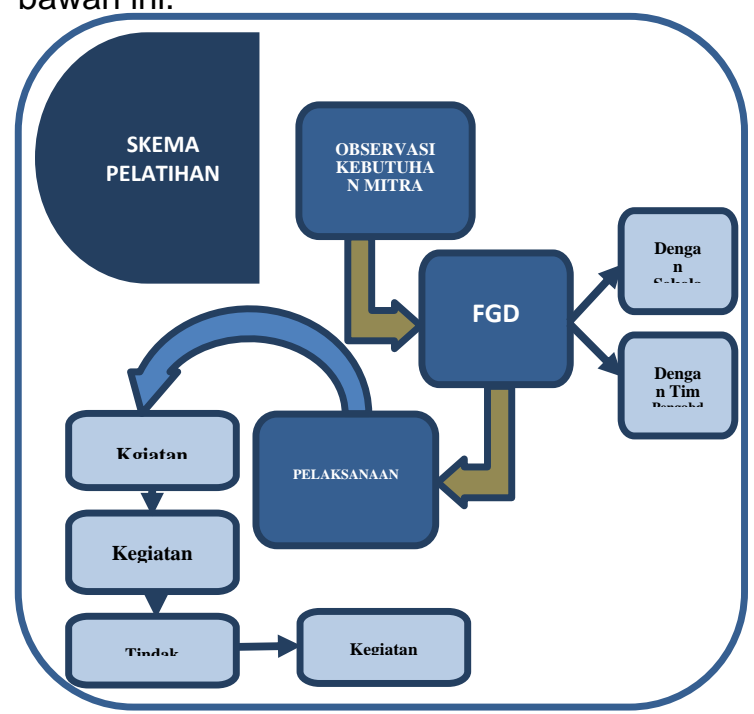

Sumber: pengabdian 2021

Gambar 1. Skema pelatihan

\section{HASIL DAN PEMBAHASAN}

Kegiatan pengabdian ini menggandeng guru sekolah sebagai mitra dimana pelatihan akan diberikan kepada guru sebagai subjek sasaran. Meskipun demikian kami coba mengembangkan peserta kegiatan dengan mengajak beberapa mahasiswa keguruan untuk ikut serta dalam pelatihan. Secara umum kegiatan diikuti oleh guru yang berlatar belakan keilmuan yang berbeda serta mengajar mata pelajaran yang beragam. Secara terperinci
Jumlah peserta bisa dilihat pada tabel di bawah ini

Tabel 1. Komposisi Peserta Berdasarkan jenis kelamin

\begin{tabular}{|lccc|}
\hline \multicolumn{1}{|c}{ Nama } & \multicolumn{2}{c|}{ Peserta } & JUMLAH \\
\hline SMP Darussalam Plus & L & P & \\
\hline SMPN 3 Lingsar & 7 & 6 & 13 \\
\hline Guru sekolah Non Sasaran & 4 & 1 & 5 \\
\hline Mahasiswa jumlah & 3 & & 3 \\
\hline \multicolumn{1}{|c|}{ jumb } & & & 17 \\
\hline
\end{tabular}

Kegiatan ini berupaya memberikan pemahaman dan kemampuan praktis kepada guru terkait pelaksanaan pembelajaran daring terutama dalam memanfaatkan aplikasi Quizziz untuk proses dan evaluasi pembelajaran. Hal tersebut berdasar pada proses observasi dan FGD (focus grup discussion) dengan guru sasaran dimana mereka belum mengetahui terkait aplikasi Quizziz.

Pelaksanaan pelatihan ini di laksanakan secara paralel dan dibagi menjadi beberapa tahapan, yaitu kegiatan awal, kegiatan inti, dan kegiatan penutup. Pada kegiatan awal panitia memfasilitasi peserta untuk masuk room meeting. Setelah itu peserta diberikan pengarahan awal pelaksanaan pelatihan yang sedang dilaksanakan. Ada beberapa hal yang ditekankan kepada peserta pelatihan diantaranya: 1). Mekanisme pelatihan yang akan dilaksanakan; 2). Tata tertib dalam melaksanakan pelatihan; dan 3). pengisian presensi.

Tahap kedua adalah kegiatan inti. Kegiatan inti di bagi menjadi 4 fase yaitu: penyuluhan, pelatihan, diskusi, simulasi. Pada tahap penyuluhan peserta diberikan pemahaman baik secara konseptual dan teori tentang pembelajaran daring beserta tips and trick. Ada beberapa hal yang ditekankan dalam penyuluhan diantaranya: tantangan pembelajaran daring, kebijakan pendidikan di masa pandemi, faktor pendukung dalam pembelajaran daring, solusi untuk pemecahan masalah pembelajaran daring. kegiatan penyuluhan bisa dilihat pada gambar tangkapan layar dibawah ini:

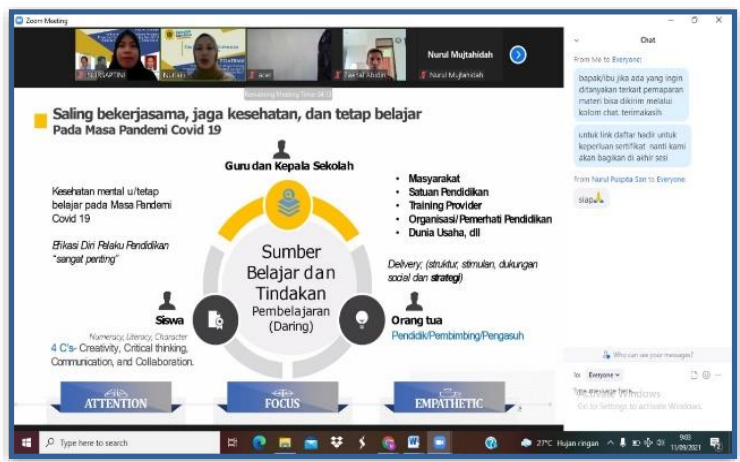

Sumber: Dokumentasi Pengabdian 2021

Gambar 2. Proses penyuluhan secara daring 
Kedua adalah tahapan pelatihan. Tahap pelatihan di bagi kembali menjadi 3 bagian; yaitu: penyampaian materi secara simulasi, pendampingan, diskusi, evaluasi. Pada tahap penyampaian materi, nara sumber mensimulasi cara penggunaan aplikasi Quizziz. Tahapan dalam simulasi mulai dari cara mengunduh aplikasi jika di gunakan dalam telephon celluler, mengakses website Quizziz, mendaftar akun, membuat materi pembelajaran. Membuat soal evaluasi atau kuis. Pada tahapan ini nara sumber berupaya agar peserta mampu mengikuti dan memahami semua komponen yang terdapat dalam aplikasi Quizziz. Kegiatan tersebut bisa di lihat pula pada gambar tangkapan layar di bawah ini.

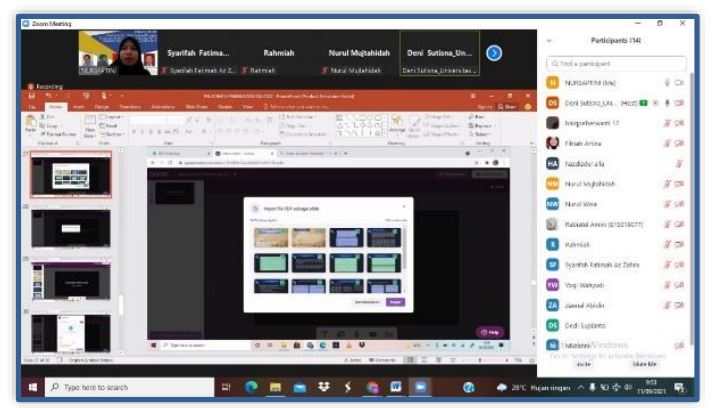

Sumber: Dokumentasi Pengabdian 2021

Gambar 3. Proses pelatihan dan simulasi

Setelah simulasi peserta dibimbing untuk menggunakan aplikasi Quizziz. Nara sumber memulai lagi dari awal dan diikuti oleh peserta. Pada tahap ini tim pengabdian kepada masyarakat berupaya untuk membimbing dan memonitor secara daring agar peserta bisa mengikuti step by step dalam menggunakan aplikasi Quizziz. Pada tahap ini juga kami membuka diskusi baik secara langsung bertanya atau menggunakan chat room pada Zoom meeting. Peserta di berikan kebebasan untuk mengemukakan kesulitan dalam menginstal atau menggunakan aplikasi tersebut. Salah satu contoh kegiatan dapat di lihat pada gambar tangkapan layar berikut ini.

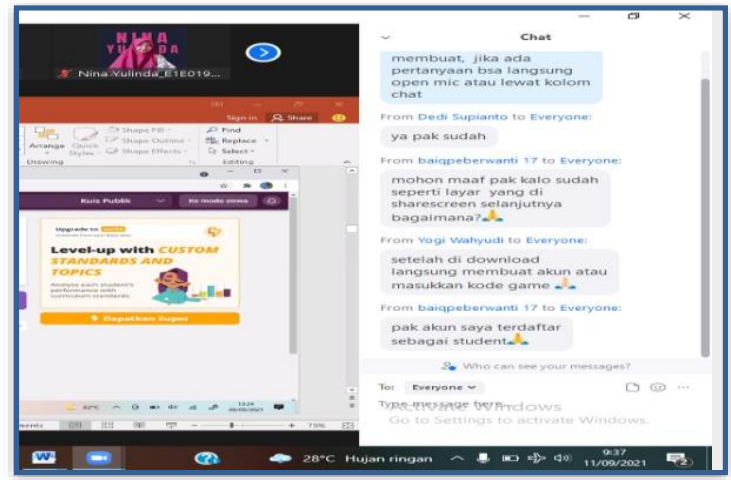

Sumber: Dokumentasi Pengabdian 2021

Gambar 4. Proses pelatihan dan pendampingan
Setelah proses pelatihan dan pendampingan kami mencoba membuka forum diskusi. Pada tahapan ini peserta memiliki kesempatan untuk mengemukakan kendala atau sesuatu yang belum mereka pahami. Ada beberapa diantara mereka yang masih menemukan kendala baik dalam penginstalan atau dalam mengoperasikan Quizziz akan tetapi tim berupaya membantu sehingga mereka mampu menggunakan atau mengoperasikan aplikasi Quizziz tersebut.

Tahapan berikutnya adalah Evaluasi. Pada tahap ini Narasumber dan tim berupaya untuk memberikan pengalaman mereka dalam menggunakan aplikasi Quizziz ini. Pertama peserta berperan sebagai siswa agar mereka memahami teknis penggunaan. kedua peserta diberikan kesempatan untuk berperan sebagai guru. Hal tersebut di lakukan bagi peserta yang sudah dianggap mampu dengan melihat kesesuaian konten soal yang telah mereka buat dan. Simulasi penggunaan Quizziz bisa terlihat seperti gambar tangkapan layar di bawah ini.

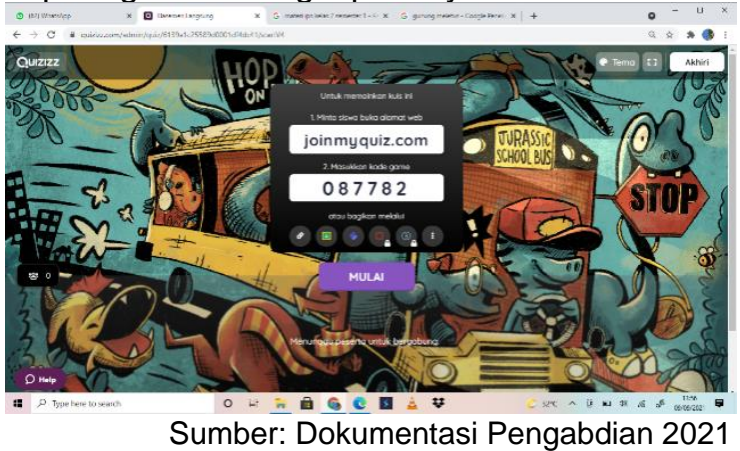

Gambar 5. Simulasi penilaian menggunakan

Quizziz.

Setelah simulasi kegiatan hari pertama telah terlaksana. Peserta di berikan kesempatan untuk mengembangkan dan memperdalam lagi agar bisa lebih memahami pemanfaatan aplikasi tersebut.

Tidak lanjut dilakukan pada hari berikutnya. Tahapan ini dilaksanakan secara langsung dimana tim pengabdian berkunjung kesekolah dan. Terlihat progres yang baik dimana sebagian besar diantara mereka sudah mampu mengoperasikan Quizziz. Ada juga beberapa yang meminta di bimbing kembali karena ada yang lupa. Oleh karena itu tim berupaya membimbing mereka kembali minimal hingga mereka mampu membuat soal pertanyaan yang akan di buat kuis atau penilaian. Berikut gambar tindak lanjut yang telah dilaksanakan. 


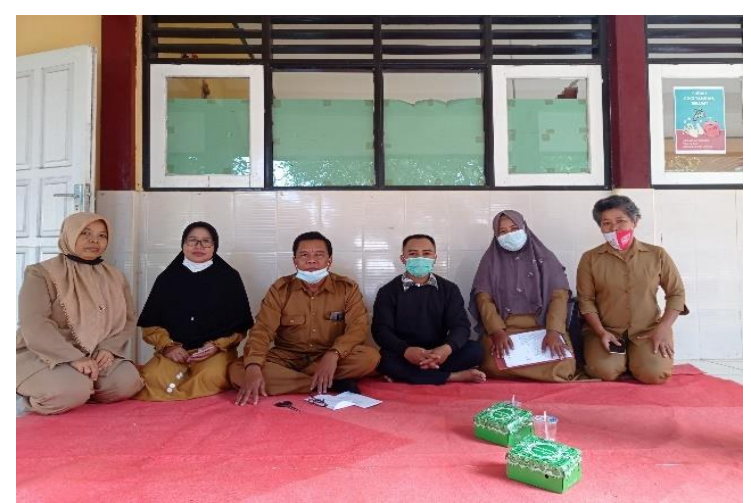

Sumber: Dokumentasi Pengabdian 2021 Gambar 6. Tindak lanjut kegiatan

Secara keseluruhan kegiatan ini telah dilaksanakan dengan baik. Hal tersebut dapat dilihat dari hasil observasi dan posttestpostest yang dilakukan setelah pelatihan. perkembangan kemampuan perkembangan kemampuan peserta pelatihan seperti yang dapat terlihat pada diagram berikut ini

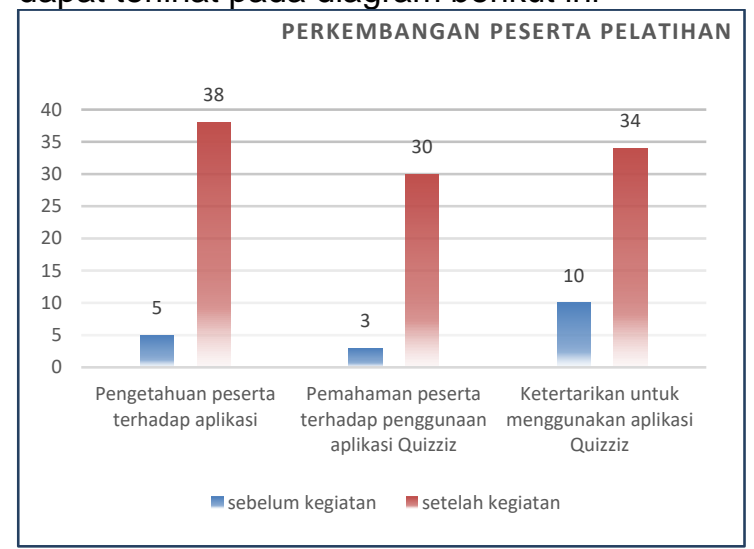

Gambar 7. Perkembangan kemampuan peserta

Berdasarkan gambar 6 di atas dapat dilihat bahwa pengetahuan, pemahaman dan ketertarikan peserta mengalami perubahan. Ada beberapa temuan berdasarkan data di atas, pertama untuk pengetahuan peserta terhadap aplikasi Quizziz mengalami kenaikan. Awalnya hanya $13 \%$ peserta mengetahui aplikasi tersebut. Yang kedua dari segi pemahaman aplikasi. Meskipun belum berhasil $100 \%$ akan tetapi perkembangan pemahaman peserta masih tinggi, dimana $79 \%$ peserta memahami dan hanya $21 \%$ yang dianggap masih perlu bimbingan lebih lanjut. Selain itu dilihat dari ketertarikan peserta dalam memanfaatkan Aplikasi Quizziz dimana sebelum dilaksanakan pelatihan hanya 14\% yang tertarik dan setelah dilaksanakan pelatihan mengalami kenaikan yang signifikan diaman $89 \%$ peserta tertarik untuk menggunakan Quizziz dalam pembelajaran daring.
Pada dasarnya proses pelatihan yang telah dilaksanakan tidak menemukan kendala yang berarti. Meski demikian ada beberapa permasalahan teknis dalam pelaksanaan pelatihan, diantaranya:1) kendala teknis. Kendala ini berkaitan dengan jaringan yang digunakan peserta. Ada beberapa diantara mereka yang keluar masuk meeting room karena jaringan internet yang tidak stabil; 2). Sumber daya manusia. dalam hal ini berkaitan degan sebagian kecil peserta yang mengalami kesulitan dalam mengikuti pelatihan. Hal tersebut dikarenakan peserta kurang familiar dengan penggunaan-penggunaan platformplatform digital dan bisa dikatakan memiliki pengetahuan yang rendah terhadap komputer sehingga hal tersebut menjadi kendala. Permasalahan diatas hanya sebagian kecil sehingga jika ditarik secara umum proses pelatihan berjalan dengan baik sesuai dengan tujuan awal.

Ada beberapa temuan berdasarkan perbincangan antara tim dengan peserta kegiatan, dimana banyak diantara Guru yang belum mengerti dan memahami cara membuat atribut yang digunakan dalam pembelajaran daring misalnya Googe Form, Gogle classroom, Penggunaan Zoom Meeting atau yang lainnya. Temuan tersebut membuka kesempatan kami untuk menjalin kerja sama dalam melaksanakan program pengabdian selanjutnya.

\section{SIMPULAN DAN SARAN}

Berdasarkan seluruh rangkaian kegiatan yang telah dilaksanakan dapat disimpulkan bahwa pelaksanaan kegiatan penyuluhan dan pelatihan berjalan baik tanpa kendala yang berarti. Hal tersebut terlihat dari pengetahuan, pemahaman, dan ketertarikan peserta pelatihan yang mengalami perkembangan yang cukup signifikan. Selain itu penelitian ini juga menjadi awal terjalinnya kerjasama untuk melaksanakan pelatihan lanjutan dalam rangka meningkatkan kemampuan guru dalam memanfaatkan teknologi digital guna pendukung pembelajaran siswa.

\section{UCAPAN TERIMAKASIH}

Untuk Ucapan terima kasih yang sebesar-besarnya kami ucapkan kepada berbagai fihak yang memiliki andil dalam program pengabdian kepada masyarakat ini. Yang pertama kami ucapkan kepada FKIP Universitas mataram atas dukungannya. Melalui dana PNBP Universitas Mataram kegiatan Pengabdian ini bisa terlaksana. Selanjutnya kepada pihak sekolah mitra mulai dari kepala sekolah, guru, serta tenaga pendidikan yang telah berpartisipasi dalam 
kegiatan ini. Semoga pelatihan yang telah dilaksanakan memberikan keterampilan baru sehingga dapat meningkatkan kualitas pembelajaran terutama dalam melaksanakan penilaian atau evaluasi pembelajaran.

\section{DAFTAR RUJUKAN}

Fauziyah, N. (2020). Dampak Covid-19 terhadap efektivitas pembelajaran daring pendidikan Islam. Al-Mau-Izhah, 2(2), 111.

Hikmat, Hermawan, E., Aldim, \& Irwandi. (2020). Efektivitas Pembalajaran Daring Selama Masa Pandemi Covid-19: Sebuah Survey Online. Digital Library, UIN SUnan Gung Djati, Bandung, 1-7. Diambil dari http://digilib.uinsgd.ac.id/30625/

Juliya, M., \& Herlambang, Y. T. (2021). Analisis Problematika Pembelajaran Daring dan Pengaruhnya Terhadap Motivasi Belajar Siswa. XII(1), 281-294.

Kusumadewi, R. F., Yustiana, S., \& Nasihah, K. (2020). Menumbuhkan Kemandirian Siswa Selama Pembelajaran Daring Sebagai Dampak COVID-19 Di SD. JRPD (Jurnal Riset Pendidikan Dasar), 1(1), 713.

Makki, M. I., \& Affaandi, M. (2019). Konsep Dasar Belajar dan Pembelajaran. pamekasan: Duta Media Publishing.

Oktavian, R., \& Aldya, R. F. (2020). Efektivitas Pembelajaran Daring Terintegrasi di Era Pendidikan 4.0. Didaktis: Jurnal Pendidikan dan IImu Pengetahuan, 20(2), 129-135.

https://doi.org/10.30651/didaktis.v20i2.47 63

Pohan, A. E. (2020). Konsep pembelajaran daring berbasis pendekatan ilmiah. Jawa Tengah: CV Sarnu Untung.

Santaria, R., \& Setiawan, E. I. (2020). TANTANGAN PEMBELAJARAN DARING DI INDONESIA Pendahuluan Pembelajaran daring adalah proses pembelajaran yang dilakukan. 5(2), 8998.

https://doi.org/https://doi.org/10.24256/kel ola.v5i2.1397

TENTANG, S. E. M. P. D. K. N. 4 T. 2020. (2020). SURAT EDARAN MENTERI PENDIDIKAN DAN KEBUDAYAAN NOMOR 4 TAHUN 2020 TENTANG PELAKSANAAN KEBIJAKAN PENDIDIKAN DALAM MASA DARURAT PENYEBARAN CORONAVIRUS DISEASE (COVID-19). 2507(1), 1-9.

Widodo, A., Nursaptini, N., Novitasari, S., Sutisna, D., \& Umar, U. (2020). From faceto-face learning to web base learning:
Volume 5, Nomor 1, Desember 2021.

p-ISSN : 2614-5251

e-ISSN : 2614-526X

How are student readiness? Premiere Educandum: Jurnal Pendidikan Dasar dan Pembelajaran, 10(2), 149. https://doi.org/10.25273/pe.v10i2.6801

Surat Edaran Nomor 4 Tahun 2020 tentang pelaksanaan kebijakan pendidikan dalam masa darurat penyebaran COVID 19, Menteri Pendidikan dan Kebudayaan Republik Indonesia. 